\title{
Process Development for Manufacturing of Cellular Structures with Controlled Geometry and Properties
}

\author{
Paulo Pinto $^{a}$, Nuno Peixinho ${ }^{a *}$, Delfim Soares ${ }^{a}$, Filipe Silva $^{a}$ \\ ${ }^{a}$ Centre for Mechanical and Materials Technologies - CT2M, \\ Universidade do Minho, Azurém, 4800-058 Guimarães, Portugal
}

Received: April 2, 2014; Revised: April 5, 2015

\begin{abstract}
This study presents experimental results on the behaviour of aluminium alloy metal structures and foams manufactured by lost-wax casting and using 3D printed components for internal structure definition. Results for tensile tests, metallurgical properties, surface quality and geometry tolerances were obtained and discussed. The analysis focused on development geometries, used for adjusting manufacturing parameters and prototype geometries intended for geometrical and mechanical validation. The results are indicative of the viability of the method for producing foam structures suitable for mechanical loading.
\end{abstract}

Keywords: aluminium foam, cellular structures, rapid prototyping $(R P)$, tensile strength

\section{Introduction}

Metallic foams are being studied as prospective materials with significant potential due to its favourable strength-density ratio which presents advantages for the development of components for the transportation industry. Such features as high energy absorption capacity combined with low density are interesting for use in stiffness related parts and passive safety structures ${ }^{1}$.

Weight reduction in the transportation industry is currently a major force driving for material and manufacturing developments. Weight reduction in vehicles cannot reduce passenger safety therefore meaning that the materials used cannot compromise stiffness and strength. Thus, it is important to correctly determine the behaviour and properties of new materials to be used in vehicles ${ }^{2}$.

Low density, high strength and excellent energy absorption in compression are favourable characteristics of metal foams that are important for the development of impact-related parts and maintaining or improving passive safety. Due to this excellent performance, there is a need for continuous improvement and to refine their manufacturing processes and production ${ }^{3}$.

Metal foams show a dependency of mechanical behaviour on factors such as structure of cells, density and properties of the base material and thickness of intricate internal walls. The efficiency obtained in the use of metallic foams in structural applications requires a detailed characterization of its deformation behaviour for different loads and different geometries. The size and shape of the cells or pores determines their properties, namely their behaviour depends on how the solid is distributed in the porous structure ${ }^{4,5}$. The manufacturing of components with precise tolerances and fracture behaviour of thin-walled parts are challenging with the currently available processes

*e-mail: peixinho@dem.uminho.pt for production of metal foams and cellular materials ${ }^{6}$. The production of a foam with controlled hole geometry, size and distribution is, therefore, an important challenge and allows the possibility to adapt the material properties to the in service specific solicitations.

This paper presents a study on the development of a manufacturing process suitable for the production of aluminium metal foams with controlled geometry and properties. The foams are of open cell type and manufactured using a process of lost wax casting while recurring to 3D printing for the internal geometry definition. With development and validation of process parameters this method has proven usefull for manufacturing cellular structures with precisely defined geometry ${ }^{7,8}$ eventually allowing further optimization of geometrical structure for mechanical loading.

\section{Materials and Experimental Methods}

\subsection{Materials}

In this study, a commercial AlSi12 alloy (A413.1) was used for the trial manufacturing process development and metal foam prototypes. The composition of the alloy is presented in Table 1. This alloy was chosen based on previous experience with casting having shown good properties for fine tuning of the manufacturing process.

The resin used in the rapid prototype (RP) machine was a photosensitive resin, DC 500 [DWS S.r.l., Zané, Italy], that is specifically designed to allow the production of high-definition, detailed parts and smooth surfaces. The composition of the resin can be found in Table 2 .

A commercial gypsum [Ranson\& Randolph, Ultra-Vest, Maumee, OH, USA] was used in the lost wax casting as investing material. The composition of the gypsum is presented in Table 3. 


\subsection{Experimental methods}

\subsubsection{Specimen geometry}

The geometries chosen for this study are presented in Figures 1, 2 and 3. These include a simpler "development geometry" (Figure 1 and Figure 2), intended to analyze in detail the manufacturing process variables, and a metal foam prototype $(\Phi=16 \mathrm{~mm} ; \mathrm{h}=40 \mathrm{~mm}$ ) (Figure 3 ), for geometrical reproducibility verification. The models were designed in a CAD software (Solidworks 2012). For the development geometry (Figure 1) the useful area considered $(22.5 \mathrm{~mm}$ in length and $16.7 \mathrm{~mm}$ width) comprises cells with quadrangular shape and with walls of three different circular sections $-1.0,0.7$ and $0.4 \mathrm{~mm}$ in diameters (Figure 1a, Figure $1 \mathrm{~b}$ and Figure $1 \mathrm{c}$, respectively). It was also designed a spiral model with $8 \mathrm{~mm}$ in height and 4 revolutions in order to analyze the fluidity of the metal. The section of the spiral's model has 0.5 mmdiameter (Figure 2).A three-dimensional model was, also, developed as shown in Figure 3. This sample is based in a base geometry of stacking of spheres with a diameter of $4 \mathrm{~mm}$. This sample was used to study the effect of each process step on sample size and geometry.

\subsubsection{Resin specimens}

The obtained models in CAD software were exported to a stereolithography (STL) machine [Digital Wax 008, DWS S.r.l., Zané, Italy]. Standard build parameters were

Table 1. Composition of the A413.1 aluminium alloy (wt.\%) (according to the manufacturer).

\begin{tabular}{ccccccccc}
\hline Element & $\boldsymbol{S i}$ & $\boldsymbol{C u}$ & $\boldsymbol{F e}$ & $\boldsymbol{M g}$ & $\boldsymbol{M n}$ & $\boldsymbol{Z n}$ & $\boldsymbol{N i}$ & $\boldsymbol{A l}$ \\
\hline Wt. \% & $11.0-13.0$ & 1.0 & 1.0 & 0.10 & 0.35 & 0.40 & 0.50 & balance \\
\hline
\end{tabular}

Table 2. Composition of the DC 500 resin (wt.\%) (according to the manufacturer).

\begin{tabular}{cccc}
\hline Element & $\begin{array}{c}\text { Multi-functional } \\
\text { acrylic monomers }\end{array}$ & $\begin{array}{c}\text { Crystalline } \\
\text { Silica } \\
\text { Cristobalite }\end{array}$ & $\begin{array}{c}\text { Radical } \\
\text { photoinitiator }\end{array}$ \\
\hline $\mathrm{wt} . \%$ & $70-90$ & $10-30$ & $0.5-3$ \\
\hline
\end{tabular}

Table 3. Composition of the R\&R Ultra-Vest gypsum (wt.\%) (according to the manufacturer).

\begin{tabular}{cccc}
\hline Element & $\begin{array}{c}\text { Crystalline } \\
\text { Silica Quartz }\end{array}$ & $\begin{array}{c}\text { High molecular } \\
\text { polyol }\end{array}$ & $\begin{array}{c}\text { Calcium Sulfate } \\
\text { Hemihydrate }\end{array}$ \\
\hline $\mathrm{wt} . \%$ & $<50$ & $>30$ & $<40$ \\
\hline
\end{tabular}

used and selected as follows: $0,03 \mathrm{~mm}$ for layer thickness; $0,04 \mathrm{~mm}$ for tool compensation; and $0,06 \mathrm{~mm}$ for hatching space. After each prototyping cycle, the resin models were cured for 30 minutes in an ultraviolet curing unit [Digital Wax Model S, DWS S.r.l., Zané, Italy] to final consolidation.

\subsubsection{LostWax casting}

The metallic specimens were obtained by lost wax casting using a vacuum/pressure casting machine [Indutherm VC 400, Walzbachtal/Wössingen, Germany]. The AlSi alloy was melt in a graphite crucible at $635^{\circ} \mathrm{C}$ on the top chamber under argon atmosphere $\left(\mathrm{p}_{1}=\mathrm{p}_{\mathrm{atm}}\right)$ while the flask was placed in the bottom chamber under vacuum $\left(\mathrm{p}_{2}=0,1 \mathrm{mbar}\right)$ at different temperatures $-\mathrm{T} 1=300{ }^{\circ} \mathrm{C}, \mathrm{T} 2=350{ }^{\circ} \mathrm{C}$ and $\mathrm{T} 3=400{ }^{\circ} \mathrm{C}$ (Figure 4a).After the alloy's melting, an over pressure of $0.75 \mathrm{bar}\left(\mathrm{p}_{3}\right)$ was added to the top chamber followed by the pouring of the metal at $635^{\circ} \mathrm{C}$ (Figure 4b) into the mold cavity $\left(\mathrm{p}_{4}=0,1 \mathrm{mbar}\right)$, thus recreating the original wax/resin tree with a metal replica (Figure 4c).

\subsubsection{Investment removal}

After each casting process, when the mold reached $500{ }^{\circ} \mathrm{C}$ was inserted into a water container at room temperature that caused the disintegration of the investment. The residual investment in the metal tree was removed in an ultrasonic water cleaner for 10 minutes.

\subsubsection{Tensile tests}

In order to analyze mechanical properties, the development geometry specimens were submitted to uniaxial tensile tests using a displacement rate of $0.5 \mathrm{~mm} / \mathrm{min}$. Tests were performed in a universal testing machine (Tinius Olsen, Model H100KS, USA) at room temperature and ambient air. The load information was obtained from the calibrated load cells on the tensile machine.

\subsubsection{Metallurgical properties}

Metallurgical properties were analyzed in all processing conditions and in three different zones [Zone $1-\mathrm{Z1}$; Zone 2 - Z2; Zone 3 - Z3 identified in Figure 5] of the developed geometry specimens (Figure 5) using an optical microscope [Axiotech, Carl Zeiss, USA].The images were analyzed using image analysis software (Image $J$ ).

Table 4 shows the number of specimens used in each type of study and method. For the fluidity analysis one Spiral specimen was used for each mold temperature. For the development geometry, metallurgical properties were performed in three different section diameters in each mold temperature and for the tensile tests three specimens were

Table 4. Number of samples used in each type of study.

\begin{tabular}{|c|c|c|c|c|c|c|c|c|c|c|}
\hline \multicolumn{11}{|c|}{ Number of samples } \\
\hline Type of study & \multicolumn{3}{|c|}{ Fluidity } & \multicolumn{3}{|c|}{ Metallurgical properties } & \multicolumn{3}{|c|}{ Mechanical Properties } & \multirow{2}{*}{$\begin{array}{c}\text { Geometrical Analysis } \\
\text { Optical Microscope }\end{array}$} \\
\hline Method & \multicolumn{3}{|c|}{ Length measurement } & \multicolumn{3}{|c|}{ Optical Microscope } & \multicolumn{3}{|c|}{ Tensile Tests } & \\
\hline Mold Temperature $\left({ }^{\circ} \mathrm{C}\right)$ & 300 & 350 & 400 & 300 & 350 & 400 & 300 & 350 & 400 & 350 \\
\hline$\varnothing_{\text {section }}=1.0 \mathrm{~mm}$ & - & - & - & 1 & 1 & 1 & 3 & 3 & 3 & 1 \\
\hline$\varnothing_{\text {section }}=0.7 \mathrm{~mm}$ & - & - & - & 1 & 1 & 1 & 3 & 3 & 3 & 1 \\
\hline$\varnothing_{\text {section }}=0.4 \mathrm{~mm}$ & - & - & - & 1 & 1 & 1 & 3 & 3 & 3 & 1 \\
\hline Spiral & 1 & 1 & 1 & - & - & - & - & - & - & - \\
\hline Prototype Metal Foam & - & - & - & - & - & - & - & - & - & 1 \\
\hline
\end{tabular}




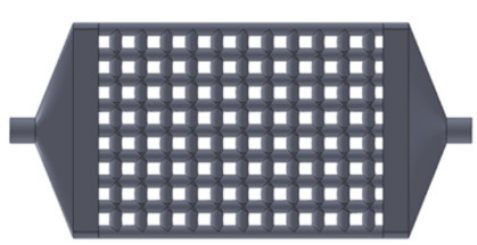

$$
\mathrm{a}-\emptyset_{\text {section }}=1.0 \mathrm{~mm}
$$



$\mathrm{b}-\emptyset_{\text {section }}=0.7 \mathrm{~mm}$

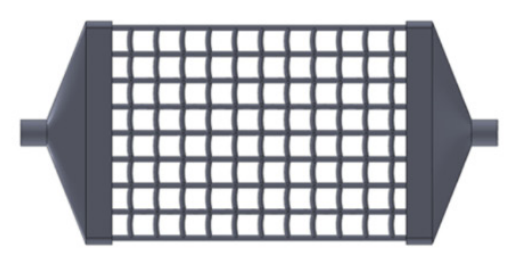

$c-\varnothing_{\text {section }}=0.4 \mathrm{~mm}$

Figure 1. Developed geometries used in this study.

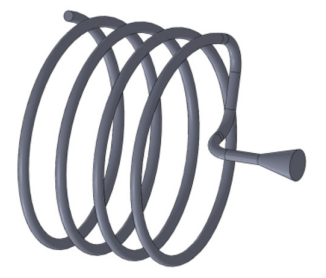

Figure 2. Spiral model $\left(\mathrm{H}=8.0 \mathrm{~mm} ;\right.$ Revolutions $\left.=4 ; \varnothing_{\text {section }}=0.5 \mathrm{~mm}\right)$.

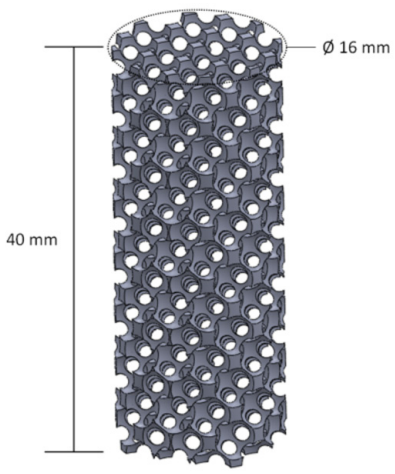

Figure 3. Prototype metal foam structure and final dimensions.
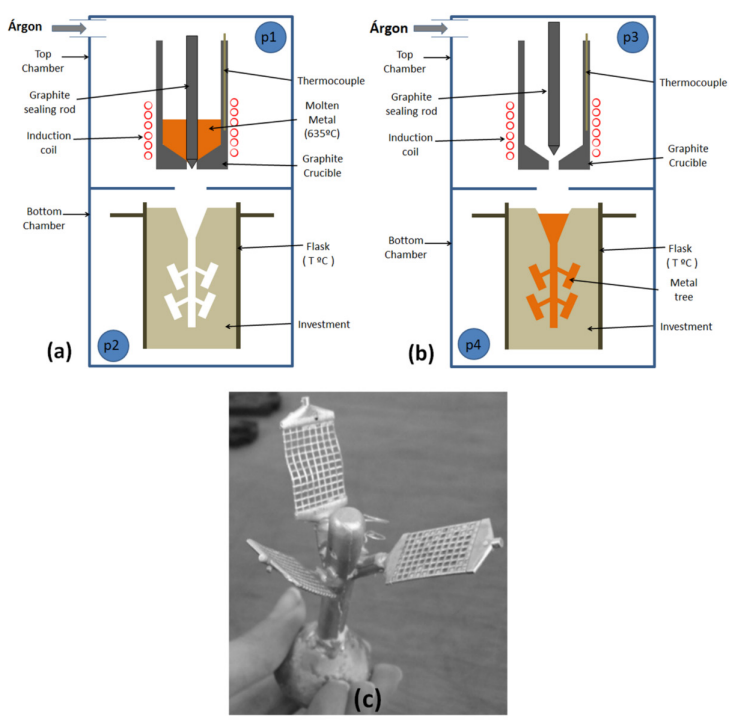

Figure 4. Shematic of lost wax casting procedure [(a) and (b)] used to obtain the metallic specimens of the development geometry and the metal foam prototype (c).



Figure 5. Detail of metallurgical analysis zones in sample according to the distance from pouring size.

used for each type of different section diameter and mold temperatures. For both the development geometry and one metal foam prototype a geometrical analysis was carried out using an optical microscope [Axiotech, Carl Zeiss, USA] to obtain micrographs at different zones of the specimens.

\section{Results and Discussion}

\subsection{Geometrical analysis of the developed geometry}

In order to evaluate the surface quality of the processed samples, at the different process stages, thickness and cellular perimeter measurements were obtained from CAD, resin and metal samples.

Table 5 presents the sample size evolution from CAD to the prototype model and the results exhibit an oversizing in this process stage. It also shows, for this kind of geometry, the accuracy loss of the prototype machine with the section wall diameter increasing. Therefore, this process stage affects resin prototypes models and consequently the final metal sample.

In Figure 6 and Figure 7a comparison is presented between the obtained cells type in different zones of the sample, in the prototyping process and in the casted samples, respectively. Figure 6 highlights that prototyping process may reveal some imperfections such as surface roughness and Figure 7 reveals some castings defects. There is no geometry variation when different zones of the specimens were analyzed.

In order to evaluate surface finishing, several measurements were made in the internal cells perimeter of the resin and casted samples. The results of these measurements are presented in Figure 8. As expected, when the section diameter is higher, the cellular perimeter is smaller for all resin and metal samples. By analyzing cellular perimeter of the resin samples it was 

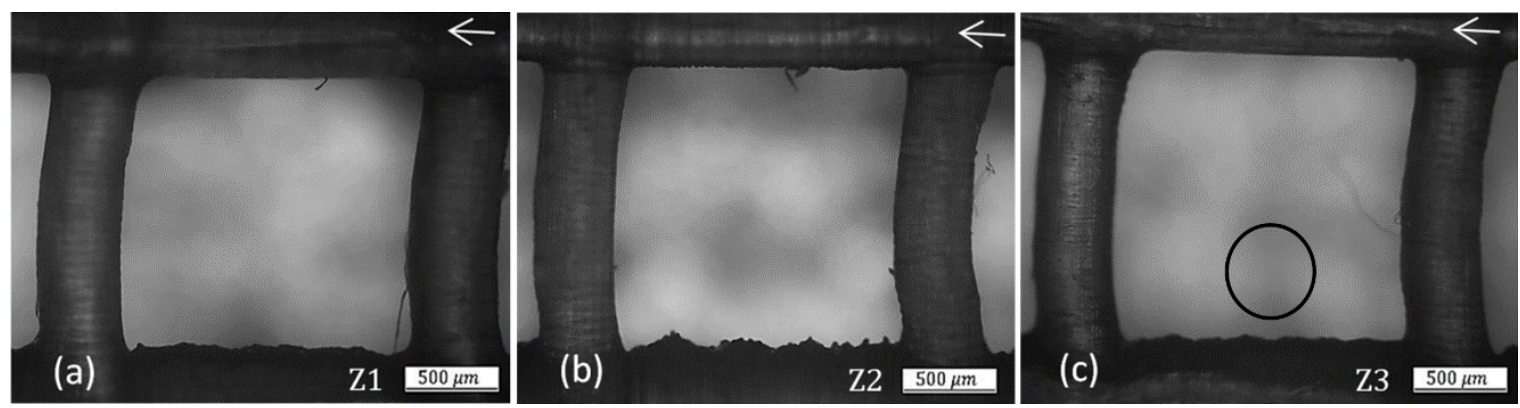

Figure 6. Prototyped model cells in defined sample zone $1 \mathrm{a}$ ), zone $2 \mathrm{~b}$ ) and zone $3 \mathrm{c}$ ) for the wall section diameter of $0.4 \mathrm{~mm}$. The arrow shows the pouring direction.
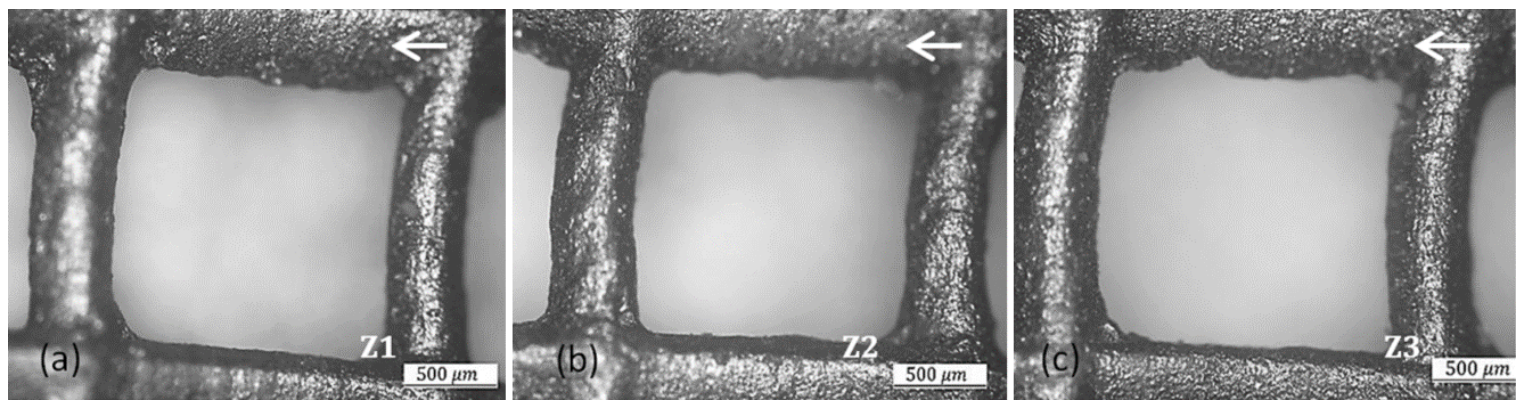

Figure 7. Metal sample cell in defined zone $1 \mathrm{a}$ ), zone $2 \mathrm{~b}$ ) and zone $3 \mathrm{c}$ ) for the wall section diameter of $0.4 \mathrm{~mm}$ and pouring temperature of $635^{\circ} \mathrm{C}$. The arrow shows the pouring direction.

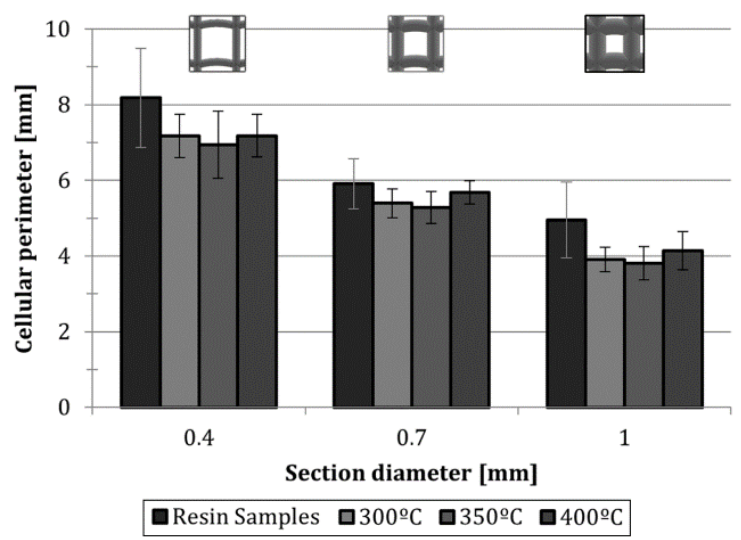

Figure 8. Average cellular perimeter of resin samples and metallic samples casted at different initial mold temperatures.

Table 5. Prototype oversizing percentage resulted from the prototype process comparing with the CAD models.

Prototype internal perimeter cell oversizing [\%]

\begin{tabular}{ccc}
\hline Øsection = 0.4 $\mathbf{~ m m}$ & Øsection $=\mathbf{0 . 7} \mathbf{~ m m}$ & Øsection=1.0 $\mathbf{~ m m}$ \\
\hline+8.5 & +17.1 & +24.4 \\
\hline
\end{tabular}

verified a higher standard deviation which may be related with the superficial roughness caused by the prototyping process. Regarding the cellular perimeter obtained for the metal samples at different mold temperatures, it was observed that the perimeter decrease in comparison with the resin samples, which may be related with the material contraction on solidification and surface roughness attenuation caused by the liquid viscosity on casting. For each section diameter the change on the mold temperature doesn't significantly changes the cellular perimeter. Therefore, for the tested pre-heating temperatures, the initial mold temperature does not appear to be a relevant variable for the final surface quality.

The fluidity of the used alloy was evaluated by length measurement of the casted spiral in the three different mold temperature conditions being the results presented in Table 6 . As expected, at a lower initial mold temperature $\left(300{ }^{\circ} \mathrm{C}\right)$ was obtained the shorter spiral length filling $(23,56 \mathrm{~mm})$, which is caused by the faster liquid metal cooling. Thus, the metal filling capability will increase if the mold temperature rises as shown by the results on Table 6 .

\subsection{Geometrical analysis of the three- dimensional metal foam prototype}

In order to analyze the geometry changes occurring in the manufacturing steps of the metal foam prototype, starting from the CAD models (Figure 9a), to resin models (Figure 9b) and finally the casted sample (Figure 9c), a dimensional inspection was performed to the cross sectioned structures. The measurement data presented resulted from the average of six measurements.

Table 7 presents measurements for the diameters d1, d2 (Figure 9a) and theirvariation percentage for the various productions steps, i.e. from the CAD model to resin model and from resin model to the metal sample. Results showed that the holes with smaller diameter (d1) displayed shrinkage percentages in the range of $\sim 5,7 \%$ in CAD-resin transition and expansion percentage in the range of $\sim 9,1 \%$ in resin-metal transition. On the other hand, holes with larger diameters ( $\mathrm{d} 2$ ) displayed $\sim 8,9 \%$ of shrinkage percentage in CAD-resin transition. The differences displayed in resin to metal transitionmay be related to the geometric complexity and to the prototyping machine accuracy. It is worth to 
CAD model

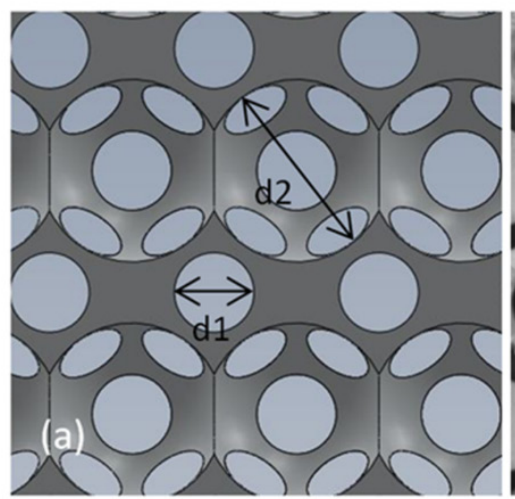

Resin model



Casted metal sample

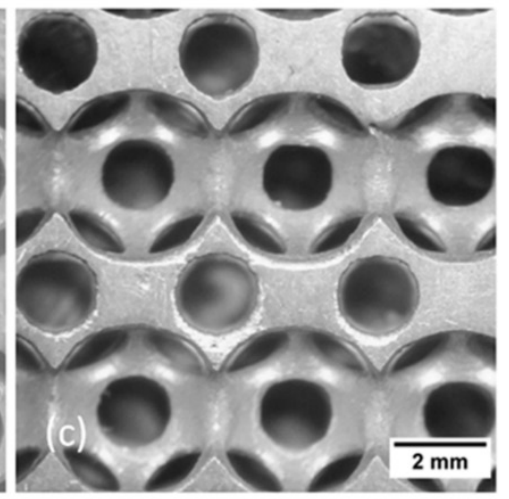

Figure 9. Production steps of the three-dimensional metal foam prototype started with the CAD model design (a); was followed by the production of the resin model in a stereolitography laser machine (b); and ended with the casted sample (c).

Table 6. Spiral length metal filling with different initial mold temperatures.

\begin{tabular}{cccc}
\hline Mold Temperature $\left({ }^{\circ} \mathbf{C}\right)$ & $\mathbf{3 0 0}$ & $\mathbf{3 5 0}$ & $\mathbf{4 0 0}$ \\
\hline Spiral length $[\mathrm{mm}]$ & 23.56 & 31.41 & 62.83 \\
\hline
\end{tabular}

Table 7. Measurements for the diameters $\mathrm{d} 1, \mathrm{~d} 2$ and their variation percentage for the various productions steps.

\begin{tabular}{lcc}
\hline & d1 & d2 \\
\hline CAD Model & $1.74 \mathrm{~mm}$ & $4.00 \mathrm{~mm}$ \\
Resin Model & $1.64 \mathrm{~mm}$ & $3.65 \mathrm{~mm}$ \\
Metal Model & $1.79 \mathrm{~mm}$ & $3.81 \mathrm{~mm}$ \\
CAD-Resindiameter variation & $-5.7 \%$ & $-8.9 \%$ \\
Resin-Metaldiameter variation & $+9.1 \%$ & $+4.6 \%$ \\
CAD-Metaldiameter variation & $+2.9 \%$ & $-4.7 \%$ \\
\hline
\end{tabular}

mention that the resin model undergoes two solidification processes: first, at the time of the construction of the model in the LASER rapid prototyping machine; and second, at the curing stage in the ultraviolet curing unit.Regarding the resin model-metal model transition, the hole expansion was $\sim 4,6 \%$. Data showed that the prototyping stage leads to a sample oversizing and the solidification process (metal shrinkage) during the casting leads to a hole expansion.

From the data of Table 1 it was possible to illustrate the geometrical behaviour (Figure 10) of the smaller holes [d1 variation - (a)] and larger holes [d2 variation (b]) on the cellular structure. Regarding CAD model-Metal model transition, holes with smaller diameter (d1) displayed an expansion percentage in the range of $\sim 2,9 \%$ and holes with larger diameters displayed shrinkage percentages in the range of $4,7 \%$.

\subsection{Metallurgical properties}

Figure 11 shows a microstructure of a sample having a section diameter of $1 \mathrm{~mm}$, poured at a temperature of $635^{\circ} \mathrm{C}$ in a mold at $350^{\circ} \mathrm{C}$, in which are indicated the alloy phases present: the (Al) solid solution phase; eutectic silicon and intermetallic precipitates (compounds of aluminum, iron and silicon) which are presented in classic $\alpha$ phase form or

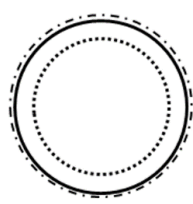

(a)

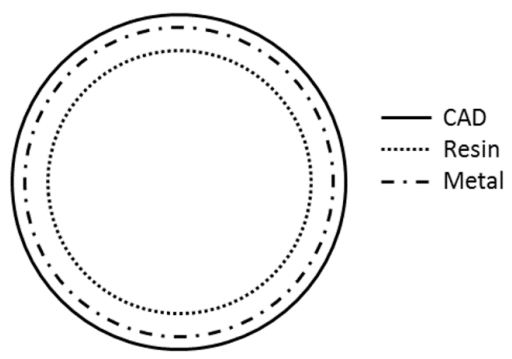

(b)
Figure 10. Geometry changes occurring in the manufacturing steps (CAD-Resin-Metal)of the smaller holes [d1 variation - (a)] and larger holes [d2 variation (b]) in the cellular structure.

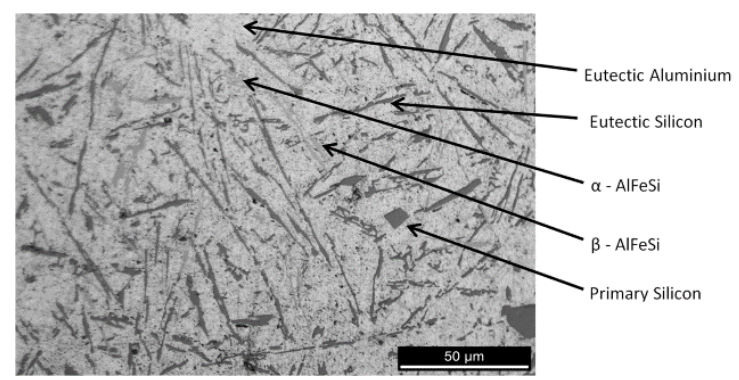

Figure 11. Microstructure of a sample with a wall section diameter of $1 \mathrm{~mm}$, poured at a temperature of $635^{\circ} \mathrm{C}$ in a mold at $350{ }^{\circ} \mathrm{C}$.

needles ( $\beta$ phase).Some primary silicon particles are, also, detected, so this commercial alloy is slightly hypereutectic ( $>12 \%$ Silicon). These blocks of primary silicon could be detrimental to the mechanical properties especially in small diameter samples, where the presence of larger blocks combined with poor dispersion along the structure can cause a local weakening.

\subsubsection{Evaluation of the eutectic silicon size with the section diameter variation}

When making a comparison between the samples processed under the same conditions but having different section diameters (Figure 12) it can be seen that the sample 



Figure 12. Microstructures of samples poured at $635^{\circ} \mathrm{C}$ in a mold at $350{ }^{\circ} \mathrm{C}$ for different wall section diameters: (a) $0.4 \mathrm{~mm}$, (b) 0.7 $\mathrm{mm}$ and (c) $1 \mathrm{~mm}-$ [Zone 2].

with the smaller wall section diameter $(0.4 \mathrm{~mm})$ display a finer microstructure.

Thus, it is observed that when the section diameter decreases the grain refinement is more visible. This occurs because thinner parts take less time to solidify, leading to finer structures. In these cases the alloy's components have smaller dimensions because of the faster solidification rate (with an increase of the nucleation rate). This is evidenced by the data shown in Table 8 where it can be observed that the average length of the eutectic silicon lamella decreases with decreasing of the section diameter of the samples. Moreover this decrease occurs in an accentuated way from the $0.7 \mathrm{~mm}$ to the $0.4 \mathrm{~mm}$ wall section diameter sample, but less significantly between from sample of $0.7 \mathrm{~mm}$ to $1 \mathrm{~mm}$ wall section diameter, with no considerable refinement of the structure. Obtaining a finer structure generally leads to an improvement of the mechanical properties of the material by ductility increasing. Thus, it is expected an improvement of mechanical properties with the decrease of the nominal section diameter of the samples.

As an extension of Table 8, Figure 13 shows the eutectic silicon length dispersion on the three different section diameter samples. It is observed that smaller samples (section diameter $0.4 \mathrm{~mm}$ ) display smaller eutectic silicon lengths below $20 \mu \mathrm{m}$. In the samples with higher section diameters $(0.7$ and $1.0 \mathrm{~mm})$ the eutectic silicon dimensions have higher variation.

\subsubsection{Evaluation of the eutectic silicon size with mold temperature variation}

Figure 14 shows the samples microstructures poured at $635^{\circ} \mathrm{C}$ with a section diameter of $0.7 \mathrm{~mm}$ for different mold temperatures: (a) $300{ }^{\circ} \mathrm{C}$, (b) $350{ }^{\circ} \mathrm{C}$ and (c) $400{ }^{\circ} \mathrm{C}$, on Zone 2. Comparing the pictures from Figure 14 it can be observed that the lower mold temperature (Figure 14a) leads to a grain refinement. This grain refinement is due to the fact that when the molten metal is poured into a mold at a specific
Table 8. Eutectic silicon average length of samples poured at $635^{\circ} \mathrm{C}$ in a mold at $350^{\circ} \mathrm{C}$ for different section diameters: $0.4 \mathrm{~mm}, 0.7 \mathrm{~mm}$ and $1.0 \mathrm{~mm}-$ [Zone 2].

\begin{tabular}{cccc}
\hline $\begin{array}{c}\text { Wall section } \\
\text { diameter [mm] }\end{array}$ & 0.4 & 0.7 & 1.0 \\
$\begin{array}{c}\text { Average length of } \\
\text { eutectic Silicon [ } \mu \mathrm{m}]\end{array}$ & $9.21 \pm 3.61$ & $18.23 \pm 6.95$ & $19.39 \pm 7.36$ \\
\hline
\end{tabular}

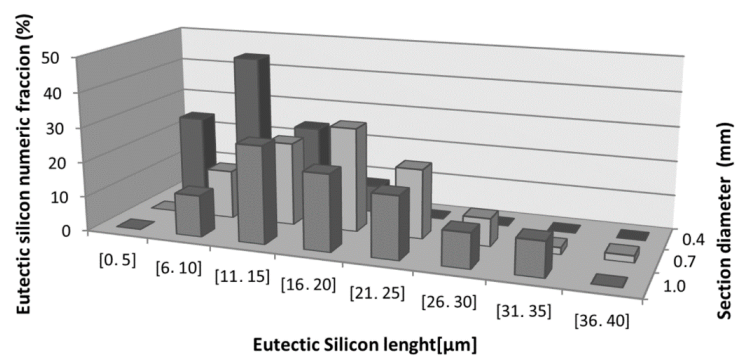

Figure 13. Eutectic silicon numeric fraction variation of samples poured at $635{ }^{\circ} \mathrm{C}$ in a mold at $350{ }^{\circ} \mathrm{C}$ for different sample wall section diameters: $0.4 \mathrm{~mm}, 0.7 \mathrm{~mm}$ and $1.0 \mathrm{~mm}$ - [Zone 2].

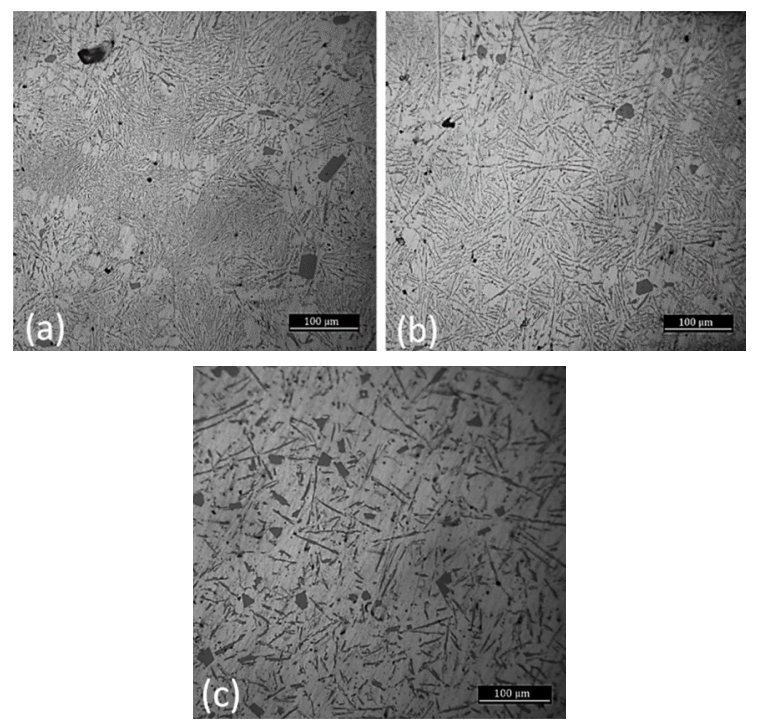

Figure 14. Microstructures of samples poured at $635^{\circ} \mathrm{C}$ with a section diameter of $0.7 \mathrm{~mm}$ for different mold temperatures: (a) $300{ }^{\circ} \mathrm{C}$, (b) $350{ }^{\circ} \mathrm{C}$ and (c) $400{ }^{\circ} \mathrm{C}-[$ Zone 2].

temperature there will be heat transfer from the metal to the mold. Thus, the greater the temperature difference between the molten metal and mold, the greater the energy transfer between them, therefore the greater the solidification rate of the metal leading to a finer structure. It is also observed the presence of dendrites in the sample whose mold temperature was 300 and $350{ }^{\circ} \mathrm{C}$ (Figure 14.a and Figure 14.b). The formation of dendrites in the structure occurred when there was a higher temperature difference between metal and mold, i.e. when the solidification rate is higher. This phenomenon is explained by the fact that for high super cooling levels the dendritic structures rate formation is higher than the rate formation of the eutectic silicon phase, which results in the appearance of dendrites in the structure ${ }^{9}$. As 
the eutectic silicon has worst mechanical properties than the modified silicon structures, it is expected that dendritic structures get more ductility leading to an improvement in mechanical properties.

Analyzing eutectic silicon average length values in Table 9 , it is possible to confirm that there was grain refinement with the decrease of mold temperature. The results presented in Figure 15 also confirm grain refinement with the mold temperature decrease and furthermore show the eutectic silicon length fluctuation on the different processed samples. It is observed that at $400^{\circ} \mathrm{C}$ of mold temperature the eutectic silicon length fluctuation is higher leading to a coarse structure due to a slower solidification rate of the molten metal.

\subsubsection{Evaluation of the eutectic silicon size with sample zone variation}

Figure 16 shows the microstructure for the sample with a section diameter of $0.7 \mathrm{~mm}$, poured at $635^{\circ} \mathrm{C}$, in a mold temperature of $350^{\circ} \mathrm{C}$ assessed in different zones: (a) Zone 1; (b) Zone 2 (c) Zone 3, in order to evaluate the variation of the microstructure along the sample. Thus, as shown in Figure 16, there are no significant differences in the different sample's zones.

In general, all the results show grain refinement with the mold temperature and section diameter decrease leading to a smaller dimension of the alloy's components, although in the different zones of the sample the dimensions of the components are the same. The dendrites appearance occurs only when the difference between molten metal and mold temperature is higher (mold at $300{ }^{\circ} \mathrm{C}$ and $350{ }^{\circ} \mathrm{C}$ ) and is expected an improvement in mechanical properties. It's pertinent to refer the presence of casting defects, such as sink marks and microporosity, in all processed samples, which are expected to negatively affect the mechanical properties.

\subsection{Tensile tests}

The development geometry prototypes (Figures 1 and 5) were submitted to tensile tests through established procedures. From the tensile tests it was possible to obtain stress-strain curves that allow the observation of the sample behaviour and the tensile strength determination. This tensile strength can be regarded as the maximum stress that the sample can withstand without rupture.

Observing the broken specimens (Figure 17) and stress-strain curves in Figure 18 (representative for all process conditions) it is verified that the samples had essentially brittle behaviour. It is noted at the beginning of the test, a region where deformation is linear, corresponding to the region of elastic behaviour of the material and finally reaches to a maximum stress, being also considered as the tensile

Table 9. Eutectic silicon average length of samples poured at $635^{\circ} \mathrm{C}$ with a section diameter of $0.7 \mathrm{~mm}$ for different mold temperatures: $300{ }^{\circ} \mathrm{C}, 350{ }^{\circ} \mathrm{C}$ and $400{ }^{\circ} \mathrm{C}-[$ Zone 2].

\begin{tabular}{cccc}
\hline $\begin{array}{c}\text { Mold Temperature } \\
{\left[{ }^{\circ} \mathrm{C}\right]}\end{array}$ & 300 & 350 & 400 \\
$\begin{array}{c}\text { Average length of } \\
\text { eutectic silicon }[\mu \mathrm{m}]\end{array}$ & $16.20 \pm 7.06$ & $18.23 \pm 6.95$ & $24.89 \pm 11.57$ \\
\hline
\end{tabular}

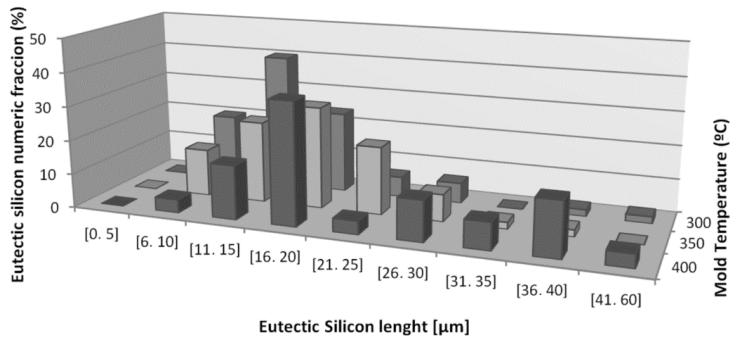

Figure 15. Eutectic silicon numeric fraction variation of samples poured at $635{ }^{\circ} \mathrm{C}$ with a section diameter of $0.7 \mathrm{~mm}$ for different mold temperatures: $300{ }^{\circ} \mathrm{C}, 350{ }^{\circ} \mathrm{C}$ and $400{ }^{\circ} \mathrm{C}$ - [Zone 2].
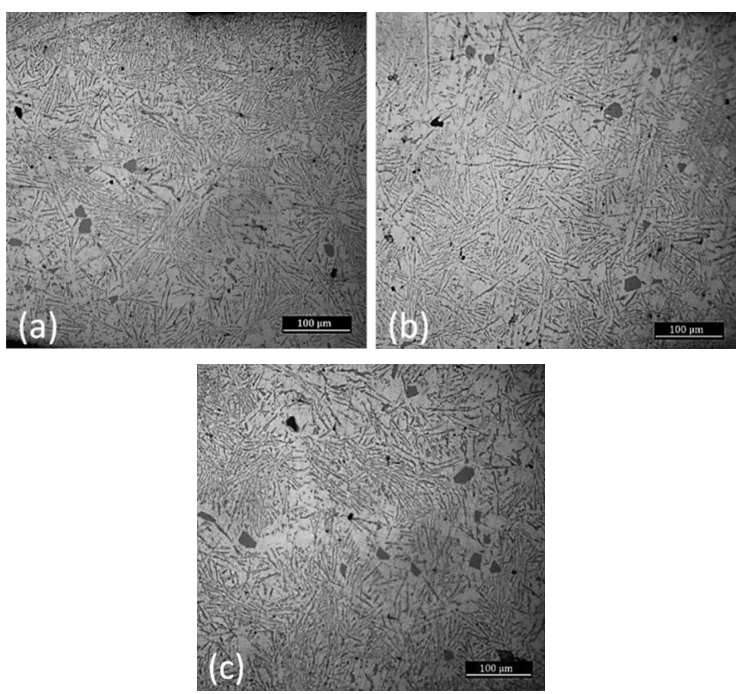

Figure 16. Microstructures of a sample with a section diameter of $0.7 \mathrm{~mm}$, poured at $635^{\circ} \mathrm{C}$, in a mold temperature of $350^{\circ} \mathrm{C}$ assessed in different zones: (a) Zone 1; (b) Zone 2 (c) Zone 3.

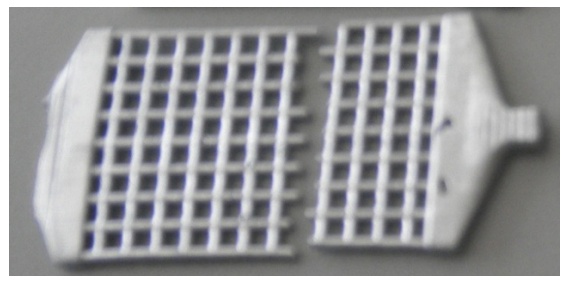

Figure 17. Representative figure of broken sample with $0.7 \mathrm{~mm}$ section diameter.

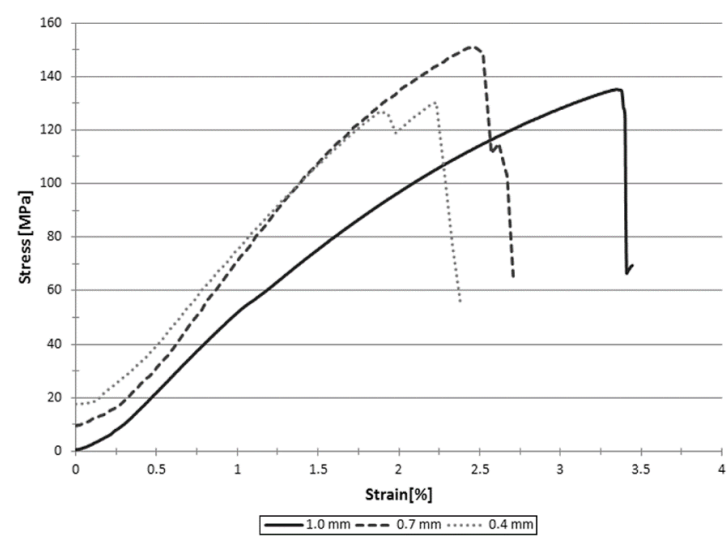

Figure 18. Stress-Strain curve of samples poured at $625^{\circ} \mathrm{C}$ into a mold temperature of $350^{\circ} \mathrm{C}$ for different section diameters. 


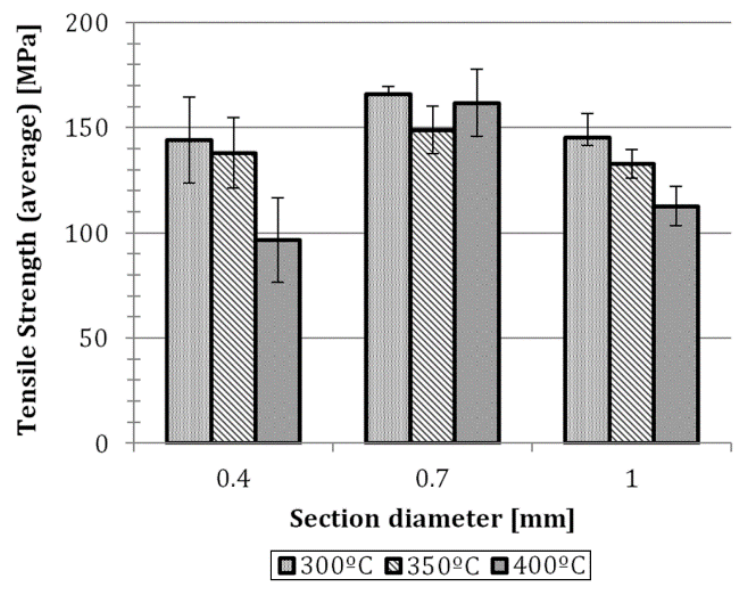

Figure 19. Average tensile strength for different section diameters $(0.4 \mathrm{~mm}, 0.7 \mathrm{~mm}$ and $1.0 \mathrm{~mm})$ and different mold temperatures $\left(300^{\circ} \mathrm{C}, 350{ }^{\circ} \mathrm{C}\right.$ and $\left.400^{\circ} \mathrm{C}\right)$.

strength of the sample. The absence of necking zone reveals a non-ductile behaviour of the samples.

Figure 19 shows the average tensile strength for different section diameters $(0.4 \mathrm{~mm}, 0.7 \mathrm{~mm}$ and $1.0 \mathrm{~mm})$ and different mold temperatures $\left(300^{\circ} \mathrm{C}, 350^{\circ} \mathrm{C}\right.$ and $\left.400^{\circ} \mathrm{C}\right)$ and reveals the $0.7 \mathrm{~mm}$ samples as the ones with better mechanical behaviour. As expected, the mechanical properties have improved with the section diameter reduction from $1.0 \mathrm{~mm}$ to $0.7 \mathrm{~mm}$ in all mold temperatures used. This improvement is related with the grain refinement that the $0.7 \mathrm{~mm}$ sample is subject to. It is noted that the samples with section diameter of $0.4 \mathrm{~mm}$ had the worst mechanical behaviour in spite of showing the finest microstructure. This may be related to casting defects found, such as sink marks and microporosity, which have a higher contribution for mechanical properties degradation while comparing to samples with higher diameter. Considering a Yield Strength of $140 \mathrm{MPa}$ for A413.1 bulk alloy $\left(2.61 \mathrm{~g} / \mathrm{cm}^{3}\right)$ and a mean value of $125 \mathrm{MPa}$ for the produced cellular foam $\left(1,49 \mathrm{~g} / \mathrm{cm}^{3}\right)$ there is an increase of specific strength of $54,5 \% / \mathrm{g}$ for the cellular material.

\section{Conclusions}

This study presents the development of a manufacturing process suitable for the production of aluminium metal foams with controlled geometry and properties. The foams are of open cell type and manufactured using a process of lost wax casting while recurring to 3D printing for the internal geometry definition. Besides material and process description, results for geometrical, metallurgical and tensile test analysis are presented for two different geometries: development geometry (geometrical, metallurgical and tensile test analysis) and prototype metal foam (geometrical analysis).

Regarding the geometrical behaviour of a characteristic cellular structure with two different internal diameters ( 11 and $\mathrm{d} 2$ ) it was observed that in CAD model-Metal model transition, holes with smaller diameter (d1) displayed an expansion percentage in the range of $\sim 2,9 \%$ while holes with larger diameters displayed shrinkage percentages in the range of $4,7 \%$.

The metallurgical analysis highlighted that when the section diameter decreases grain refinement is more visible. Grain refinement also occurs with mold temperature decrease. It was also shown that eutectic silicon length dispersion on smaller samples (section diameter $0.4 \mathrm{~mm}$ ) is smaller (lengths below $20 \mu \mathrm{m}$ ) while in the samples with higher section diameters $(0.7$ and $1.0 \mathrm{~mm})$ the eutectic silicon dimensions have higher variation. Furthermore, eutectic silicon length fluctuation was observed with different mold temperatures. It was noted that at $400^{\circ} \mathrm{C}$ of mold temperature the eutectic silicon length fluctuation is higher leading to a coarser structure due to a slower solidification rate of the molten metal. It is pertinent to refer the presence of casting defects, such as sink marks and micro porosity, in all processed samples, which are expected to negatively affect the mechanical properties.

Tensile properties were analyzed for different section diameters $(0.4 \mathrm{~mm}, 0.7 \mathrm{~mm}$ and $1.0 \mathrm{~mm})$ and different mold temperatures $\left(300{ }^{\circ} \mathrm{C}, 350{ }^{\circ} \mathrm{C}\right.$ and $\left.400{ }^{\circ} \mathrm{C}\right)$ and revealed the $0.7 \mathrm{~mm}$ samples as the ones with better mechanical behaviour. Samples with section diameter of $0.4 \mathrm{~mm}$ had the worst mechanical behaviour in spite of showing the finest microstructure which was related to casting defects found, such as sink marks and micro porosity that can have a higher contribution for mechanical properties degradation while comparing to samples with higher diameter.

The development and validation of process parameters by the presented method was analyzed in view of geometrical, metallurgical and strength properties. The results are indicative of the viability of the method for producing foam structures suitable for mechanical loading. It can also be used for manufacturing cellular structures with precisely defined geometry eventually allowing further optimization of geometrical structure for mechanical loading.

\section{Acknowledgements}

The authors are grateful to the Portuguese Foundation for Science and Technology (FCT) who financially supported this work, through the project PTDC/EME-PME/115668/2009.

\section{References}

1. Banhart J. Manufacture, characterisation and application of cellular metals and metal foams. Progress in Materials Science. 2001; 46(6):559-632. http://dx.doi.org/10.1016/ S0079-6425(00)00002-5.

2. Song H, Fan Z, Yu G, Wang Q and Tobota A. Partition energy absorption of axially crushed aluminum foam-filled hat sections. International Journal of Solids and Structures. 2005; 42(910):2575-2600. http://dx.doi.org/10.1016/j.ijsolstr.2004.09.050.
3. Banhart J. Metallic foams: challenges and opportunities. In: Zitha P, Banhart J and Verbist G, editors. Proceedings Eurofoam 2000. Bremen: MIT-Verlag; 2000. p. 13-20.

4. Olurin O, Fleck N and Ashby M. Deformation and fracture of aluminium foams. Materials Science and Engineering A. 2000; 291(1-2):136-146. http://dx.doi.org/10.1016/S09215093(00)00954-0.

5. Pinto P, Peixinho N, Silva F and Soares D. Compressive properties and energy absorption of aluminum foams with 
modified cellular geometry. Journal of Materials Processing Technology. 2014; 214(3):571-577. http://dx.doi.org/10.1016/j. jmatprotec.2013.11.011.

6. Smith B, Szyniszewski S, Hajjar J, Schafer B and Arwade S. Steel foam for structures: a review of applications, manufacturing and material properties. Journal of Constructional Steel Research. 2012; 71:1-10. http://dx.doi.org/10.1016/j.jcsr.2011.10.028.

7. Matz A, Mocker B, Muller D, Jost N and Eggeler G. Mesostructural design and manufacturing of open-pore metal foams by investment casting. Advances in Materials Science and Engineering. 2014; 2014:421729. http://dx.doi.org/10.1155/2014/421729.

8. Cingi C, Niini E and Orkas J. Foamed aluminum parts by investment casting. Colloids and Surfaces. A, Physicochemical and Engineering Aspects. 2009; 344(1-3):113-117. http://dx.doi. org/10.1016/j.colsurfa.2009.01.006.

9. Kang HS, Yoon WY, Kim KH, Kim MH and Yoon YP. Microstructure selections in the undercooled hypereutetic Al-Si Alloys. Materials Science and Engineering A. 2005; 404(12):117-123. http://dx.doi.org/10.1016/j.msea.2005.05.041. 